\title{
SOBRE ÉTICA, MERLEAU-PONTY E FENOMENOLOGIA: ECOS DE UM DIÁLOGO COM RENAUD BARBARAS
}

\author{
On ethics, Merleau-Ponty and phenomenology: echoes of a dialogue with Renaud Barbaras
}

Sobre ética, Merleau-Ponty y fenomenología: ecos de un diálogo con Renaud Barbaras

\begin{abstract}
Resumo: O artigo retoma um diálogo da autora com Renaud Barbaras em que versavam sobre o projeto de investigação de uma ética a partir do pensamento de Merleau-Ponty e busca, doravante, aprofundar questões-chave de tal diálogo. Assim, ora perscrutando as dificuldades para se pensar uma ética a partir de uma filosofia cujo solo é fenomenológico e, pois, descritivo - o que se oporia à perspectiva propriamente prescritiva da ética, para Barbaras - ; ora, ao contrário, voltando-se para a relação recíproca entre a disposição fenomenológica do pensamento e a ética - segundo compreende a autora -, o fato é que na lida com tais questões, ver-se-á se insinuando ao longo do texto os três traços que dão o tom do seu contorno: (i) as aproximações e dissonâncias entre ética e fenomenologia, (ii) a ética que deriva daí - ou pelo menos alguns dos seus traços - e, por fim, o fluxo de uma amizade - no sentido dos antigos - vivida no debate destas questões: aquela entre a autora e Renaud Barbaras, filósofo a quem o dossiê em mãos - ou em vista! - rende homenagem.
\end{abstract}

Palavras-chave: Barbaras; Merleau-Ponty; Ética; Fenomenologia.

\begin{abstract}
This article follows up on a conversation between its author and Renaud Barbaras, reflecting on a project of investigation of ethics based on the thought of Merleau-Ponty, by addressing key questions resulting from this conversation in more depth. It does so by exploring the difficulties of thinking ethics from a phenomenological, hence, descriptive, philosophy starting point - which, for Barbaras, would be opposed to the prescriptive perspective proper to ethics; and, on the contrary, by looking at the reciprocal relation between the phenomenological disposition of the thinking and ethics - as the author understands it. Dealing with such questions, three lines appear progressively in the text, giving its outline: (i) the approximations and dissonances between ethics and phenomenology, (ii) the ethics that derivates from there - or at least some of its lines, and at last (iii) the flow of a friendship, born from debating these questions, between the author and Renaud Barbaras, philosopher to whom this text pays tribute.
\end{abstract}

Keywords: Barbaras; Merleau-Ponty; Ethic; Phenomenoloy.

Resumen: El artículo retoma un diálogo de la autora con Renaud Barbaras en que versaban sobre el proyecto de investigación de una ética a partir del pensamiento de Merleau-Ponty y busca, en adelante, profundizar cuestiones clave de tal diálogo. Así, ora escrutando las dificultades para pensar una ética a partir de una filosofía cuyo suelo es fenomenológico y, pues, descriptivo - lo que se opondría a la perspectiva propiamente prescriptiva de la ética, para Barbaras -; por el contrario, volviéndose hacia la relación recíproca entre la disposición fenomenológica del pensamiento y la ética - según comprende la autora -, el hecho es que en la lectura con tales cuestiones, se verá insinuando a lo largo del texto los textos (2) la ética que deriva de ahí - o al menos algunos de sus rasgos - y, por fin, el flujo de una amistad -, en el sentido de los antiguos - vivida en el debate de estas cuestiones: aquella entre la autora y Renaud Barbaras, filósofo a quien el dossier en manos - o en vista! - rinde homenaje.

Palabras clave: Barbaras; Merleau Ponty; Ética; Fenomenología.

\section{Do início - um diálogo.}

A amizade, esta relação sem dependência, sem incidente,

onde entra a simplicidade da vida, passa pelo reconhecimento da estranheza comum que não permite falar dos nossos amigos, mas apenas falar-lhes, não fazer disso um tema de conversas (ou de artigos), mas o movimento da compreensão onde, falando, eles conservam, mesmo na maior familiaridade, a distância infinita, esta separação fundamental a partir da qual o que separa, torna-se relação. M. Blanchot, L'Amitié
Como se pode depreender já no título enunciado, este texto toma como base não a obra de Renaud Barbaras, mas um diálogo de fato, isto é: será fiado não a partir do exame da obra do autor - que, sabemos, é vasta -, mas de uma troca de palavras iniciada em Paris, em setembro de 2015, e continuada, por vias ora epistolar, ora em conversas presenciais, nos anos que se seguiram. Tomo, pois, tal diálogo como evento-provocador do que aqui versaremos; e o texto ele mesmo como expressão (assistemática) dos seus ecos. De Merleau-Ponty, o outro filósofo concernido no título de que falamos, tomaremos como referência alguns dos seus escritos, especialmente Phénoménologie de la perception, Signes e Le Visible et l'invisible. De mim, o esforço para fazer aparecer um pensamento, feito de ouvidos, leituras, interrogações 
e intuição - "penetrada pela experiência histórica", como diria Franklin Leopoldo e Silva ao se referir a certo filósofo. Isto, permitam-me, em linhas que, espero, não serão muitas, mas, em todo caso, algumas serão - já que ainda não sei dizer em haikai - um dos meus maiores desejos.

Retomemos, pois, o diálogo-provocador.

No início, a comunicação de um projeto em uma conversa descontraída em uma das mesas do l'Ecritoire (refiro-me ao café situado à Place de la Sorbonne, em Paris): - Estou trabalhando em uma pesquisa, cujo objeto é uma ética na obra de Merleau-Ponty (disse eu). O que recebeu de Barbaras a seguinte observação: - Trata-se de uma questão difícil. Alguns alunos meus se voltaram para ela, mas nenhum chegou a bom termo (mais ou menos isso, é o que permanece na memória).

Em seguida, por vias digitais e longínquas, eu escrevia: "pois sim, também considero uma questão bem exigente, mas como ela me persegue desde o mestrado (findo há dez anos) cá sigo com ela! Na conversa entusiasmada e apressada quando do encontro em Paris, não me ocorreu de lhe colocar a questão: i. segundo compreende, quais são os motivos da dificuldade da tematização de uma ética a partir do pensamento de Merleau-Ponty? ii. Por que considera que aqueles trabalhos que você conhece a esse respeito não chegaram a bom termo? Pergunto-lhe porque serão, sem dúvida, respostas que me darão a pensar. No meu processo de trabalho, diálogos assim são sempre fecundos. E, considerando a distância posta e o meio de comunicação possível, mesmo respostas minimalistas já me seriam de bom tom!" (cito trechos de uma correspondência por via eletrônica, datada de 2015).

Barbaras respondeu: "não vejo como é possível deduzir de uma abordagem fenomenológica, ou seja, descritiva, uma ética, que envolve necessariamente, por sua vez, uma dimensão prescritiva. Por exemplo, mesmo que a ontologia leve a sublinhar a importância da arte no que diz respeito ao desvelamento da carne, ou seja, ao acesso ao ser, disso não se pode concluir que devamos valorizar ou privilegiar esse modo de ser em nossa vida. De fato, conheço vários estudantes que quiseram se defrontar com esse problema, mas nenhum deles conseguiu ir até o final. Não quer dizer que seja impossível, mas é certamente muito difícil. Trata-se de colocar o problema de uma maneira certa, o que exige estabelecer em que sentido da ética é relevante falar em ética no âmbito da fenomenologia [...] Mas, justamente, é por isso, por causa dessa dificuldade que é instigante trabalhar sobre esse problema: é um verdadeiro desafio filosófico" (sigo citando correspondências por meio eletrônico).

Disse eu, então, em uma última missiva desse período da conversação: "Concordo totalmente com você: (i) 'mesmo que a ontologia leve a sublinhar a importância da arte no que diz respeito ao desvelamento da carne, ou seja ao acesso ao ser, disso não se pode concluir que devamos valorizar ou privilegiar esse modo de ser em nossa vida'; (ii) 'Trata-se de colocar o problema de uma maneira certa, o que exige estabelecer em que sen- tido da ética é relevante falar em ética no âmbito da fenomenologia'. É disto que venho me ocupando... vamos ver aonde vai dar..."

\section{Dos primeiros ecos: sobre as dificuldades para pensar uma ética no âmbito de uma abordagem fenomenológica}

\author{
A reflexão radical é consciência de sua própria \\ dependência \\ em relação a uma vida irrefletida \\ que é sua situação inicial, constante e final. \\ Merleau-Ponty - prólogo da Phénoménologie \\ de la perception.
}

Por que a fenomenologia não se prestaria ao pensamento de uma ética? Questão importante, porque é a tomando na forma afirmativa que chegamos à dedução de que a filosofia de Merleau-Ponty, sua ontologia, sendo ela de abordagem fenomenológica, guardaria, por isto, grande dificuldade às tentativas de tematizar nela uma ética. Tais dificuldades - e não impedimentos - consistiria, para Barbaras, como o vimos um pouco acima, no teor descritivo da fenomenologia em contraposição ao traço necessariamente prescritivo da ética. Aqui, numa primeira visada, penso que o que se evidencia e se coloca em questão - isto é: põe-se a interrogar a fim de adentrar o problema - é, duma parte, o caráter prescritivo da ética (toda ética é ela prescritiva? Ou, doutro modo, é a prescrição aquilo que determina a ética? E, ainda: a prescrição é suficiente para determinar uma ação ética?) e, doutra, o real alcance do teor descritivo fenomenologia (a fenomenologia se limita à descrição, o seu alcance acaba aí? O caráter descritivo de tal disposição de pensamento se contrapõe à ação? A que a compreensão advinda da descrição nos envia? Sim, sei, as indagações são muitas... mas sendo elas ecos honestos do diálogo que me acompanha - fecundadas, pois, por ele -, considerei por bem deitá-las aqui.

Em todo caso - e talvez concordemos com isso -, trata-se de questões prenhes de questões..., como disse certa feita Machado de Assis (refiro-me ao capítulo final de Quincas Borba - que sempre me apraz lembrar e costumo fazê-lo!), afirmação exclamativa a que ele acrescenta: ... que nos levariam longe... - e não seria a QUESTÃO, a disposição interrogativa, a atenção rigorosa a ela, justamente a vocação da filosofia? Aliás, a esse respeito, vale lembrar que no percurso merleau-pontyano, em geral, os confrontos com outros pensamentos se mostram no desvelamento das questões - na persecução delas por diferentes temáticas, desdobrando-as -, mais do que na refutação ou defesa deste ou daquele filósofo - e talvez esteja, sobretudo aí, a fecundidade do seu pensamento. É que Merleau-Ponty desconfiava que

Há razão para temer que também o nosso tempo rejeite o filósofo em si mesmo e que, mais uma vez, a filosofia seja apenas nuvens. Pois filosofar é procurar, é afirmar que há algo a ver e a dizer. Ora, hoje, quase não se procura. "regressa-se," "defende-se” uma ou outra tra- 
dição. As nossas convicções fundam-se menos sobre valores ou verdades percebidas do que sobre os vícios e os erros das que detestamos (Merleau-Ponty, 1989, p. 45).

Embora aqui estejamos nos voltando para as dificuldades concernentes à tematização de uma ética a partir da filosofia de Merleau-Ponty - com razão apresentadas por Barbaras - e não propriamente lidando com a negação da possibilidade de tal tarefa, a incursão nela me trouxe à lembrança afirmações longínquas de alguns profissionais da filosofia que diziam ser impossível a empreitada, justificada tal afirmação com o fato de Merleau-Ponty não ter ele mesmo se voltado para uma ética de forma sistemática. Ora, penso, não estaria aí um testamento de morte do pensamento? "[...] uma filosofia, como uma obra de arte, é um objeto que pode suscitar mais pensamentos do que aqueles que nela estão 'contidos”, descreve o filósofo (Merleau-Ponty, 2009, p. 253), e com isso nos envia ao sentido do impensado que, observará Marilena Chauí (2002, p. 40), "não é o que estaria ausente como privação, mas aquilo cuja ausência é promessa e antecipação [...] ausência que conta no mundo porque não é um vazio, mas ponto de passagem [...] Não é lacuna que preenchemos, mas trilha que seguimos". O impensado, como dimensão da filosofia, mora na dobra pensamento-engajamento. Engajamento este, em cujo rigor, isto é: o efetivo encontro com os outros e a insistência no mundo, brota o movimento, a liberdade do pensamento - e da ação. E, por certo, o rigor aí será abertura, não adequação. "Quando se trata do pensar”, diz, por fim, Merleau-Ponty, recorrendo a Heidegger, "quanto maior for a obra feita - o que absolutamente não coincide com a extensão e a quantidade dos escritos -, mais rico será, nessa obra, o impensado, ou seja, aquilo que, através dessa obra e apenas por ela, vem para nós como nunca ainda pensado" (Merleau-Ponty, 2008, p. 260).

Ademais, fico a ruminar, se dizemos que da fenomenologia - sua abordagem descritiva - não é possível depreender uma ética, não ficaríamos, com tal afirmação, no âmbito das especialidades e serventias dos pensamentos e, pela mesma via, no âmbito do dualismo ontológico?: o pensamento objetivo-analítico-explicativo serve para pensar uma ética; pensamento compreensivo-descritivo, não. Mas se Ser há tanto em uma via de pensamento como noutra, numa ele pode ser pensado no crivo de uma ética; noutra, não? Numa ele é ético, por assim dizer, noutra não? ${ }^{1}$

Mas se na vida vivemos às voltas com questões éticas, compreendidas nas nossas disposições para com os outros no mundo, se algo neste sentido nos apela sempre, é traço daquilo que somos, da nossa verdade (o que significa: não se trata a ética apenas de uma ideia na constelação das ideias eternas, nem se reduz ela a um conceito racional), então uma via de pensamento (no embate entre fenomenologia e

\footnotetext{
1 E aqui me ocorre uma afirmação de Merleau-Ponty ao enveredar pela questão da verdade e os diferentes - e mesmo antagônicos - pensamentos que dela se ocupam: "Não há senão uma solução", diz ele, "mostrar que há transcendência entre as filosofias, certo, não redução a um plano único, mas que, nesse escalonamento em profundidade, elas se reenviam, mesmo assim, uma a outra, tratando-se, apesar de tudo, do mesmo Ser" (Merleau-Ponty, 2009, p. 237).
}

pensamento clássico ou objetivo) é verdadeira, presta-se à verdade do ser, outra não? Ou então, para pensar o ser em sua inteireza, temos sempre que lançar mão de ontologias dispares, por assim dizer, e o emendarmos como a um monstro? Tal perspectiva, afinal, parece restringir à ontologia clássica o domínio pelo qual se pergunta efetivamente pelo ser, já que não vejo como prescindir da questão ética.

$\mathrm{E}$, para terminar estas ruminações - que insistiram em acompanhar essas linhas -, se a percepção de uma ética no pensamento de Merleau-Ponty me surgiu no curso das leituras da obra do autor, se ela não foi posta de início, como hipótese na formulação de um objeto de pesquisa em cujo curso buscaria comprovar, o que dizer disso? Isso se explicaria pela ausência da devida atenção aos conceitos em sua exatidão? O não devido cálculo do que o filósofo disse e por isso cheguei a um resultado inadequado, errado? Mas aqui nos socorre novamente o já explicitado sobre o impensado como dimensão do pensamento...

Assim, a saber, no percurso que trilho, a insistente dedicação à releitura de textos do autor se deve ao fato de que a busca de uma ética a partir da filosofia de Merleau-Ponty não se justificaria no encontro de afirmações inéditas do autor que nos dariam o aval para tal fim - motivo pelo qual nos daríamos, sobretudo, à procura e exame de inéditos, disponibilizados publicamente ou não, na procura de um achado! A pesquisa a que me dedico finca-se, com efeito, na compreensão de que há na filosofia merleau-pontyana, ao longo de sua obra, tanto uma ética implícita, quanto elementos conceituais para tematizar uma ética. Donde a lida com textos de diferentes períodos do autor em um movimento de articulação, diferenciação contextual e atenção para o que neles perdura (e/ou inova) e dão sustentação ao que acabamos de dizer. Dizendo doutro modo é assim: lendo-o, encontrei uma ética; releio-o e leio-o para tematizar e explicitar conceitualmente a ética que compreendi ali.

Vejo, pois, na filosofia merleau-pontyana estes dois lugares de atenção: o horizonte de uma ética, porque compreendemos que a contraposição da sua nova ontologia às perspectivas antropológicas metafísicas fornece indicações e caminhos para uma possível ética que assuma como fonte inexorável o fenômeno radicalmente integral da existência, cujo horizonte se enraíza aquém da normatividade racional a priori - e neste registro nos são caras as noções de coexistência e mundo comum engendradas na sua filosofia e consumadas no exame que o filósofo faz do corpo e da percepção. E uma ética latente, porque compreendemos que o sentido do novo encaminhamento que Merleau-Ponty dá às questões que concernem à própria filosofia e sua tarefa guarda implicações éticas, isto é: o seu estilo, para utilizar um termo do filósofo, repousa em compreensões do mundo, dos homens e das coisas, cujo engajamento perpetrado por suas interpelações filosóficas guarda ele próprio uma conduta ética.

Mas voltemos aos núcleos aos quais concernem às indagações inicialmente elaboradas, aquelas que se voltam propriamente para o problema da relação 
entre ética e prescrição e do alcance da descrição fenomenológica - tal qual explicitamos no primeiro parágrafo deste item.

$$
* * *
$$

Digo, de início, no que alude à disposição fenomenológica da filosofia merleau-pontyana como dificuldade à perscrutação de uma ética, que, ao meu ver, o que lhe incute dificuldade não está na prescrição, mas na relação entre fenomenologia e ação - assim como, numa questão correlata, o que me interpela sobremaneira, não é tanto a oposição entre descrição e crítica, mas a relação entre disposição descritivo-compreensiva e ação. Entretanto, não vejo em tais interpelações motivo de impedimento no que toca ao exame de uma ética na obra de Merleau-Ponty, mas, isto sim, núcleos de passagem para bem estabelecer o sentido da Ética que nela perscrutamos; tanto quanto pistas para definir os contornos da procura na obra do autor. E, examinando-a, com ele (Merleau-Ponty) caminhamos justamente na direção de uma ética não prescritiva - e, vale dizer, as perspectivas de uma ética não prescritiva não se encontram apenas na filosofia merleau-pontyana, lembremos, por exemplo, da ética sistematizada por Espinosa no séc. XVII, bem como aquelas tematizadas a partir da filosofia heideggeriana, a exemplo da obra de Zeljko Loparic, Ética e finitude (2004).

É que, por certo, como Hannah Arendt - autora controversa -, Merleau-Ponty percebia "que a justiça [- termo correlato à ética de que falamos -] pouco tinha a ver com a objetividade no sentido corrente do termo" (Arendt, 1991, p. 14). Ora, qual é vigor da prescrição? A objetividade que se poderia depreender do seu assento apriorístico no que toca ao envio ao ato - e ao julgamento dele. Da prescrição à obediência. Da obediência (misto de coação interna alimentada pelo medo - que, como diz Hannah Arendt em texto de homenagem a Lessing, é "a piedade que sentimos por nós mesmos” (Arendt, 1991) - e externa, pois que o mundo é vasto, vive comigo e me ultrapassa, dilatando-me, tem lá seus perigos, e caminhando nele tenho que o medo não nasce só de mim) ... da obediência, dizíamos, à reprodução. Reprodução objetiva que nem sempre tem a ver com uma disposição ética, cujo sentido primordial é a persistência num tipo de relação com os outros que guarda um sentido de comunhão: comunhão no pertencimento, comunhão na fruição - questão que será basilar ás perspectivas de reparação de situações de desigualdade, não de diferença, no viver. Ora, será o nosso comum pertencimento ao mundo, o entrosamento vivo dos homens, das coisas e outras espécies, nossa atenção voltada para isso, e não simplesmente a adoção de uma prescrição bem definida, que poderá dar lugar à criação de modos de vida que acolham a coexistência e suas complexas exigências. E numa vida estreitada na coação, sabemos, não há criação, há adequação ao dado. Estranhando ou recusando explicações e justificativas dadas a priori e insistindo no mundo da vida como solo das nossas condutas, julgamentos e ações, nas ambiguidades que se nos apresentam aí, o que desperta é o apelo à criação - no que toca à ação, tanto quanto ao pensamento e à linguagem.

Mas, sabemos, decorrem do vício operativo da reflexão posturas muitas vezes bem-intencionadas que insistem numa ideia inexistente - isto é: aquela que precede as coisas, o mundo - contra uma sociedade real (aquela em que somos engajados sensivelmente e da qual, como corpo vivo, somos sujeitos - mas "sujeito de carne e movimento"), buscando-se, com isto, submeter (ou enquadrar) o existente a uma ideia que possa totalizá-lo numa explicação e, no mais das vezes, prescrever-lhe os caminhos para o futuro certo. Tais disposições - sejam elas conformadas num indivíduo, num grupo ou numa organização -, sempre entusiasmadas demais em afirmar a absoluta verdade e eficácia daquilo que propõem, na maioria das vezes preferem chamar de fracas ou não maduras, por não terem feito ainda a devida reflexão - aquelas disposições dissonantes que, assentadas na complexidade de que é feita a vida, não se alinham a certas vias (únicas) de prescrição - do sentido, do pensamento, da ação. Ah! De costume, aquelas também clamam submissão - de um sentido a outro, de um pensamento a outro, de uma ação a outra, de uma organização a outra. É que existe uma ordem hierárquica em suas formulações.

A persistência no entrosamento vivo que vigora no mundo, na relação real com ele, aduz, tal qual a filosofia de Merleau-Ponty, a um mundo não abstrato, em cujo solo a liberdade se vê às voltas com o que pode e tem que fazer - é ela também situada ali. A liberdade aí será experiência, não será, pois, o poder de elisão ou evasão do mundo em favor da sua constituição intelectual - aquele correlato à autonomia do sujeito constituinte universal -, mas de, inserida inevitavelmente no mundo, abri-lo num processo indefinidamente aberto. Será neste sentido que o filósofo francês se referirá a um sujeito de carne e movimento (Cf. Merleau-Ponty, 1995). A liberdade situada de Merleau-Ponty é a contrapartida de sermos sempre já pertencimento, situação. Contrapartida, pois, do que a disposição fenomenológica intrínseca à sua filosofia o ensina a ver: um mundo aquém de toda tese - coesão sem conceito, pré-reflexivo.

Assim, para retomar as questões a mim apresentadas por Barbaras (doravante me refiro ao limite - não prescritivo - do exemplo da " importância da arte no que diz respeito ao desvelamento da carne" na filosofia merleau-pontyana e a compreensão disto como limite a uma ética), quando dizemos alhures (refiro-me ao livro intitulado Arte e verdade em Merleau-Ponty: ecos de um entrelaçamento) que temos nas compreensões abertas pela investigação sobre o entrecruzamento entre arte e verdade na filosofia de Merleau-Ponty as bases para uma ética sustentada em seu pensamento, não estamos concluindo com isso que devamos valorizar ou privilegiar o modo de ser da arte em nossa vida, prescrevendo-o como a conduta certa... não se trata de prescrever uma conduta, mas de dar atenção àquilo a que a experiência da arte nos remete... posto ser a disposição ética pensamento e ação entrelaçados. Não se trata, doutro modo, de privilegiar um modo de ser em nossa vida. Um modo seria sempre um modo - e restariam tantos 
outros - e do privilegio resultaria seja a negação da vida ela mesma em sua inteireza - suas exigências práticas, por ex., no caso de privilegiar a arte -, seja a recusa de outros modos de existir, outras vias por onde o ser se mostra, vive. Assim, a questão está, num primeiro momento, na atenção àquilo que a arte no dá (o quiasma, o pertencimento, a coexistência, o inacabamento, a criação, o inexplicável); em um segundo, às consequências de tal atenção: se ela me dá a tudo isso - dá-me a tal experiência do ser - e o faz também em termos da possibilidade de reflexão, poderá fazer-se horizonte das minhas condutas?

Ademais, a arte, cuja obra reúne e cuja origem é, afinal, inexplicável, dá-nos a uma verdade que tem no mundo sensível o seu solo e na incompletude (em que também se insere todo e qualquer conceito) suas veredas. Como abertura, ela dá-nos ao estranhamento do que nos parece dado, estremece preconceitos acerca da verdade como ingênua "adequação", desloca certezas. Neste sentido, a obra de arte é ela mesma subversiva: mostra-nos a nós mesmos numa vida aberta e irremediavelmente entrelaçada e irredutível a qualquer tipo de dominação final. Aqui vemos um emblema de resistência às tentações totalitárias ainda que este ou aquele lugar de poder projete dominá-la, ainda que a arte se faça obra em campos e circunscrições políticas diversas - o que ela nos dá, ao fim e ao cabo, é pertencimento, indivisibilidade (ou reversibilidade) e inacabamento.

Pertencimento, indivisibilidade e inacabamento são conceitos entrecruzados, um remete ao outro, um envia ao outro, só existindo assim. O pertencimento - o Ser aí merleau-pontiano - indica-nos a condição irremediável de sermos sempre já junto a outrem - os outros, as coisas, o mundo -, solo em que germinam todas as ondulações do ser, sua história, seu acontecimento. A espessura de tal condição será a carne do mundo. "A carne do mundo", descreverá Merleau-Ponty (2009, p. 303), “é indivisão deste Ser sensível que sou, e de todo o resto que se sente em mim". A indivisibilidade se funde nos contornos desta situação, posto que o que toco me toca; o que olho me olha. Indica-nos uma situação inultrapassável de co-abertura infinita, de cujo exame vemos surgir o enigma da totalidade, para utilizar os termos do filósofo - e o infinito negativo / non finito. Neste sentido, coisas, homens e mundo são termos entrelaçados, seu cerne é o co-pertencimento. O inacabamento, por fim, é a solicitação de um ser que não se mostra senão nesta relação - articulação de todas as coisas no movimento da reversibilidade a que nos referimos -, cujo espaço entre guarda um entrelaçamento sobre o qual não se tem posse, nada acaba em si e, no entanto, existe - co-existe.

O estatuto ontológico do inacabamento é a coexistência, dirige-se ao que não sou eu, numa perspectiva egocêntrica, e não se finda no que é nós, como grupo, povo, pátria, seu horizonte é o de uma comunhão alargada que tudo entrelaça, em que, numa inscrição temporal, faz com que cada tempo seja tempo do mundo, e no sentido topológico cada canto não seja senão canto do mundo. De um mundo que nos é casa e, como tal, guarda o sentido da unidade diferenciada a que Merleau-Ponty se refere.
Deste modo, temos que o sensível, solo e chave conceitual na filosofia de Merleau-Ponty, não encerra o seu pensamento em uma estética, tal qual compreendida em sua acepção corrente, se não que nos oferece os elementos de ancoragem da ética e da política.

É na perspectiva em que vimos tateando até aqui, que ao contrário da oposição ao pensamento de uma ética tendo em vista a fenomenologia, o que temos, segundo compreendo, é a fenomenologia como uma disposição de pensamento com consequências éticas intrínsecas ao seu próprio fazer - haja vista o que ela, ao fim e ao cabo, ensina-nos: o "maior ensinamento da redução [fenomenológica] é a impossibilidade de uma redução completa" (Merleau-Ponty, 1990, p. 11). Isto é: na atitude ou disposição fenomenológica, ao nos voltarmos para as coisas mesmas, ao tomarmos com rigor as interrogações que nos lançam a tal conduta, vemo-nos abarcados naquilo pelo que perguntamos. Neste sentido, dirá o filósofo francês, "toda redução é eidética: ela não nos coloca na posse da nossa existência” (Merleau-Ponty, 1996c, p. 69). Deste modo, a disposição fenomenológica nos dá a ver/compreender o que é derivado, o que é "expressão segunda” (Merleau-Ponty, 1945, p. 3), ajudando-nos a compreender e a indagar, a saber, o assento e estatuto da prescrição.

E isto - refiro-me às consequências intrínsecas à fenomenologia -, em última instância, pode ser afirmado tomando como referência mesmo a fenomenologia husserliana, em relação à qual, como sabemos, Merleau-Ponty, em certa medida, afastou-se (mas disto trato em outro escrito); pois já lá se encontravam as bases fundamentais para a Ética que ensaio: i. a impossibilidade da redução total; ii. o outro como realidade irrecusável; iii. o comum pertencimento ao mundo da vida e, em consequência, a contingência e o inacabamento; um mundo selvagem, por assim dizer - donde o filósofo alemão permanecer às voltas com o problema do solipsismo -, afinal o "tecido intencional" é feito do meu corpo e das coisas, não há como o cindir (Merleau-Ponty, 2008, p. 272). E, decerto, é a isto que se deve a outra medida que faz com que Merleau-Ponty se demore perto de Husserl radicalizando-o, isto é: desdobrando as consequências da sua filosofia. "Querendo ou não”, dirá em todo caso Merleau-Ponty,

[...] contra seus planos e segundo sua audácia essencial, Husserl desperta um mundo selvagem e um espírito selvagem. As coisas estão lá [...] em pé, insistentes, esfolando o olhar com suas arestas, cada qual reivindicando uma presença absoluta que não é co-possível com as das outras, e que no entanto todas possuem ao mesmo tempo, em virtude de um sentido de configuração cuja ideia não nos é dada pelo "sentido teorético" [...] Os outros também estão presentes (já estavam presentes com a simultaneidade das coisas), não de saída como espíritos, nem sequer como "psiquismos", mas tais, por exemplo, como os encontramos na cólera ou no amor, rostos, gestos, palavras, aos quais, sem pensamento interposto, respondem os nos- 
sos - a ponto de às vezes voltarmos contra eles as suas palavras antes mesmo que estas nos tenham atingido, com tanta certeza, com mais certeza do que se tivéssemos compreendido -, cada qual prenhe dos outros e confirmado por eles em seu corpo (Merleau-Ponty, 2008, p. 294295).

Ainda no quesito da relação entre fenomenologia e ação, se o maior ensinamento de tal disposição do pensamento é aquele no qual passamos os olhos há pouco - a possibilidade de redução completa, e isso nos sugere a busca por "assegurar nossos passos nesse país” (Merleau-Ponty, 2009), no país da não redução da pluralidade a uma consciência constituinte, uma representação, e aos riscos da prescrição de uma única via de existência. Tal ensinamento, porém, é anterior à formulação filosófica, é compreensão fincada em nossas experiências e que se nos aparece como atitude no mundo da vida:

Ora, se a fenomenologia é um movimento antes de ser uma doutrina, se se deixa conhecer como um estilo "antes de ter chegado a uma plena consciência filosófica” é porque se desenvolve, antes de mais, como atitude, sendo em nós que encontramos o seu sentido e unidade, não se confinando a um exercício de exegese textual [a autora cita o prólogo da Phénoménologie de la perception] (Matos Dias, 2006, p. 2).

Ao contrário, a fenomenologia como movimento vivido antes de ser doutrina incide no próprio fazer filosófico, deslocando-o em seu escopo e tarefa, em seu alcance. Será decerto a intuição inicial de uma "filosofia vivida em vez de uma vida filosófica" (Leopoldo e Silva, 2018, p. 16) que levará Merleau-Ponty a radicalizar as consequências da fenomenologia na direção que apresentamos até aqui. "O que posso dizer”, dirá ele, “é que a filosofia me apareceu desde logo como qualquer coisa de extremamente concreta, de modo nenhum como construção de conceitos, de sistemas, mas, antes, como expressão, elucidação, como se queira dizer, do que vivemos, todos, e do que nós vivemos de mais concreto" (Merleau-Ponty, 2016, p. 147).

$$
* * *
$$

"O caráter fundamental da fenomenologia nos induz a pensar a ética como um desdobramento criativo essencialmente vinculado à filosofia da ação" é o que Franklin aduz na sua leitura do que venho examinando, explicitando (Leopoldo e Silva, 2018a, s.n.). Ação que nascida na aproximação às próprias coisas, da compreensão correlata à descrição do real, reside na abertura, no movimento e na intersecção: nem totalitarismo, nem ceticismo, pois. Liberdade ao rés do chão. O real, apontará Merleau-Ponty (1945, p. 5), “é um tecido sólido, ele não espera nossos juízos para anexar a si os fenômenos mais aberrantes, nem para rejeitar nossas imaginações mais verossímeis”. E compreensão, significa não estar de acordo com o que vemos, mas fazer o esforço, que por vezes nos re- pugna, de compreender: assumir a realidade tal qual se nos mostra. Será apenas a partir de tal disposição, de tal compromisso, que a ação - como agir racional no mundo da vida - vigorará efetivamente, a saber, na perspectiva de guarda da comunhão no mundo da vida, quando a isso se destina. Do contrário, as ações fundadas em uma consciência apriorística prescritiva resvalarão para o totalitarismo, duma parte, ou pelo menos, doutra, estarão fadadas à ineficácia, por assim dizer. Melhor, duma e doutra parte, estarão as ações fadadas à impotência: porque se firmam numa invenção mediada por suspeitas, conveniência da ignorância e vontade de totalização; porque querem o que não podem e, como tal, nunca terão: a vida, ainda que violentada e restringida, vige, excede a qualquer projeto de totalização ou resolução final, afinal, a história nos ensina, a vida, insubmissa, sempre perdura, cria-se, nasce, abrindo vias de insubordinação. "A racionalidade”, comentará Merleau-Ponty (1945, p. 15), "é exatamente medida pelas experiências nas quais se revela”. E continua:

Existe a racionalidade, quer dizer: as perspectivas se entrecortam, as percepções se confirmam, um sentido aparece. Mas ele não deve ser posto à parte, transformado em Espírito absoluto ou em mundo no sentido realista. O mundo fenomenológico é não o ser puro, mas o sentido que transparece na intersecção de minhas experiências e na intersecção de minhas experiências e daquelas de outrem [...]. Pela primeira vez a meditação do filósofo é consciente o bastante para não realizar no mundo e antes dela os seus próprios resultados. O filósofo tenta pensar o mundo, outrem e a si mesmo, e conceber suas relações. Mas o Ego meditante, o "espectador imparcial" [...] não encontram uma racionalidade já dada, eles "se estabelecem" e a estabelecem por uma iniciativa que não tem garantia no ser e cujo direito repousa inteiramente no poder efetivo que ela nos dá de assumir nossa história. O mundo fenomenológico não é a explicitação de um ser prévio (Merleau-Ponty,1945, p. 15).

Dito isto, sigamos adiante na perscrutação da ética que nos ocupa.

\section{Da ética que ecoa a coexistência infinita sugerida na filosofia de Merleau-Ponty- uma}

ética indireta

\section{[...] no entanto eu me ultrapasso mesmo sem o delírio, sou mais do que eu quase normalmente. Clarice Lispector - Perto do coração selvagem.}

Para seguirmos na perscrutação de uma ética no pensamento merleau-pontiano, importa demarcar com alguma precisão o lugar da ética na filosofia do autor. Ao buscarmos isto, penso que o que nos aparece, pouco a pouco, é o largo alcance da originalidade do do seu pensamento. A dificuldade maior para a precisão do lugar da ética na filosofia de Merleau-Ponty está no estabelecimento de tal lugar no 
contorno singular de sua filosofia. Como se sabe, este teor de originalidade está no caráter pré-reflexivo do pensamento como origem do filosofar, atestando a prioridade do mundo comum sobre o caráter analítico e objetivo da relação com o mundo. Ora, esta prioridade repercute na Ética, que deixa de ser um desdobramento da ontologia e passa a partilhar a posição da relação originária - e aqui me atravessa a lembrança de um título de Levinas: L'éthique comme philosophie première.

Mas, antes mesmo de seguirmos adiante, uma indagação nos interpela: por que começar um texto em que se deseja explicitar traços de uma ética a partir de Merleau-Ponty citando Clarice? Não, não o faço com a intenção de tecer relações teórico-filosóficas-acadêmicas sobre uma e outro, de demonstrar aproximações, proceder a uma análise comparativa etc. Se há aproximações, é por causa do que são e não do meu esforço - e, aqui, isso basta, não as procurarei examinar. Mas por que então? Por que Clarice Lispector aqui? Por compreender encontrar nela a proximidade do Ser pelo qual Merleau-Ponty pergunta, pelo insistente amor ao mundo - para lembrar Hannah Arendt - declarado em seus respectivos escritos, cada um à sua maneira. Ser e Mundo estes que ancoram e lembram a ética de que falamos aqui.

$$
* * *
$$

A filosofia de Merleau-Ponty pertence a um campo de compreensão e busca que se opõe ao determinismo e fixação temporal e à abstração conceitual com fins de exatidão empreendida no dualismo ontológico entre sujeito e objeto - ideia e coisa e em seu correlato método lógico-matemático. Ao acentuar, entretanto, a crítica à abstração conceitual, não busco, doravante, fazer pouco do conceito, dispensar o trabalho por ele exigido. Com efeito, em última instância, aquilo para o que nos voltamos aqui é a compreensão - se prezamos, de fato, o rigor - de que o conceito - cuja análise demonstrativa é, em longa escala no trabalho filosófico, reconhecida como o único lugar deste último tanto quanto do rigor - é, também ele, alusivo. O que significa: o conceito não totaliza a realidade, a verdade, o Ser, e o que faz, quando da pretensão de totalização, é distanciar-se dela. Disto emergem questões pungentes para a filosofia e o seu fazer acadêmico, para o discurso filosófico. "Em reação contra uma filosofia de tipo idealista, kantiana ou cartesiana,” notará o filósofo francês - mas não Barbaras, o outro! -, "a filosofia da existência se traduziu em primeiro lugar para nós pela preponderância de um tema inteiramente outro, o tema da encarnação" (Merleau-Ponty, 2000, p. 254). "Uma boa parte da filosofia fenomenológica ou existencial”, dirá Merleau-Ponty (1996b, p. 74),

[...] consiste em se espantar com esta sorte de inerência de mim ao mundo e de mim a outrem, a nos descrever este paradoxo e esta confusão, a fazer ver o vínculo do sujeito e do mundo, do sujeito e dos outros, em lugar de explicar, como o faziam os clássicos, por qualquer recurso ao espírito absoluto.

Será decerto este movimetno de pensamento a que Merleau-Ponty pertencia que o levará a tomar a experiência filosófica de Bergson como signo de um novo rumo da filosofia. Neste sentido, fazendo referência ao filósofo, deixará ver em seu Éloge de la Philosophie que

[...] não se trata [na conduta filosófica] de explicar a vida, mas de a decifrar, como um pintor, diz mais ou menos Bergson, decifra um rosto. É preciso reencontrar "a intenção da vida, o movimento simples que corre através das linhas, que as liga umas às outras e lhes dá uma significação”. Eis aí uma sorte de leitura de que somos capazes porque trazemos em nosso ser encarnado o alfabeto e a gramática da vida, mas que não supõe sentido acabado nem em nós nem nela (Merleau-Ponty, 1989, p. 30).

Donde a compreensão de que o sentido nasce na intersecção de todas as coisas - "sentido em ação" -, na qual não há lugar para o "conforto soberano da consciência" que deixa cair fora de si todos os detalhes de que a vida é feita (Merleau-Ponty, 1989, p. 30). Decerto, nesta perspectiva, as tentativas de decifração da vida - assim como a decifração de um rosto, como se delineia acima - guardaria sempre uma margem enigmática ateada pelo que há de contingente e indizível - no rosto, na vida. Ora, dirá Merleau-Ponty, "se eliminarmos do nosso espírito a ideia de um texto original de que a nossa linguagem seria a tradução ou a versão cifrada, veremos que a ideia de uma expressão completa não faz sentido, que toda linguagem é indireta ou alusiva, é, se se prefere, silêncio" 61 - razão pela qual tratar-se sua ontologia, a que chama de nova, de uma ontologia indireta ou intra- ontologia. Uma ontologia, pois, na qual "o modo de significação é indireto: eu-outrem- o mundo deliberadamente misturados, implicados um no outro, exprimidos um pelo outro, numa relação lateral..." (Merleau-Ponty, 1996c, p. 49).

Para Merleau-Ponty a recusa às filosofias da consciência - como assinala em sua obra inacabada, Le Visible et l'Invisible - não se dá apenas por transformarem o mundo em ideia de mundo, devaneio, e “por desfigurar o ser do ‘sujeito' reflexivo", cindindo-o e concebendo-o como puro pensamento; mas, igualmente, "por tornar impensáveis suas relações com outros 'sujeitos' no mundo que lhes é comum” (Merleau-Ponty, 2009, p. 66). A bem dizer, tal perspectiva o acompanha desde os seus primeiros trabalhos (La Structure... Phénoménologie de la Perception), cujo escopo era restituir o "mundo da percepção" e, como tal, o pensamento e a relação com os outros a que a percepção nos inicia: "mostrar [...] como a relação com outrem e o pensamento retomam e ultrapassam [...] a percepção que há nos iniciado à verdade" (Merleau-Ponty, 2000, p. 42). "Nossas pesquisas”, dirá em texto publicado na Revue de Métaphysique et de Morale em 1962 (Un inédit de Maurice Merleau-Ponty), 
[...] devem então nos conduzir finalmente a refletir sobre esse homem transcendental ou essa "luz natural" comum a todos que transparece através do movimento da história - sobre esse Logos que nos assinala por tarefa trazer à palavra um mundo até então mudo - da mesma forma, enfim, que sobre esse Logos do mundo percebido que nossas primeiras pesquisas encontravam na evidência da coisa [...]. O estudo da percepção não podia nos ensinar senão uma "má ambiguidade", a mistura da finitude e da universalidade, da interioridade e da exterioridade. Mas existe, no fenômeno da expressão, uma "boa ambiguidade”, isto é, uma espontaneidade que realiza o que, a considerar os elementos separados, parecia impossível, que reúne num só tecido a pluralidade das mônadas, o passado e o presente, a natureza e a cultura. $A$ constatação dessa maravilha seria a metafísica mesma, e daria ao mesmo tempo o princípio de uma moral (Merleau-Ponty, 2000, p. 47; 48). ${ }^{2}$

Nos contornos da ontologia explorada por Merleau-Ponty - aquela que a disposição fenomenológica do seu pensamento alcança -, vemos então o surgimento do que o autor tomará como carne do mundo: entrecruzamento fecundado pelo sensível que nos remete à vida anônima ou à generalidade em que cada um de nós vive uma trama - ou um drama - singular. Afinal, avaliará Renaud Barbaras (2009, p. 105), “o sensível é isto que não aparece senão recuando diante do olhar, não se mostra senão se retirando na própria mostração. Ele é caracterizado por uma certa ausência no coração da presença”. É, pois, a essa "generalidade do Sensível em si, esse anonimato inato do Eu-mesmo que" Merleau ponty chamara "carne" (Merleau-Ponty, 2009, p. 181). A carne, dirá ainda ele,

[...] não é matéria, não é espírito, não é substância. Seria preciso, para designá-la, o velho termo "elemento", no sentido em que era empregado para falar-se da água, do ar, da terra, e do fogo, isto é, no sentido de uma coisa geral, a meio caminho do indivíduo espaço-temporal e da ideia, espécie de princípio encarnado que importa um estilo de ser em todos os lugares onde se encontra uma parcela sua. A carne é neste sentido um "elemento" do Ser. Não fato ou soma de fatos e, no entanto, aderência ao lugar e ao agora. (Merleau-Ponty, 2009, p. 181-182).

\section{A carne do mundo empreendida por Merleau-}

\footnotetext{
2 Aqui, penso, conviria tecer considerações sobre filosofia da ambiguidade, ceticismo e contra-ceticismo - "o ceiticismo é a ambiguidade suportada; e a filosofia da ambiguidade, a ambiguidade concebida ou assumida" (Merleau-Ponty, 2000, p. 331) - ; tanto quanto, a partir daí, aprofundar o que se chama "boa ambiguidade" e má ambiguidade", e, por fim, mostrar as relações da filosofia da ambiguidade tal como Merleau-Ponty a compreende com o tema da criação - o que poderia muito bem ser feito em um exame acurado da entrevista anexa a Parcours Deux (2000), cujo foco é a conferência L'Homme et l'adversité, proferida pelo filósofo em 10 de setembro de 1951, em Genova; tanto quanto das Entretiens avec Georges Charbonnier e autres dialogues (2016). Isto, porém - embora a questão tematizada neste artigo, penso, solicite-o - não será feito doravante.
}

-Ponty, que designa comum pertencimento e "estilo de ser", isto é: comunhão e singularidade, envia-nos à igualdade e à diferença como traços constitutivos do ser. A compreensão disto, porém, não indica, no que toca aos homens, a igualdade em condições de vida - ou, noutra inscrição, a igualdade em ato dos direitos humanos -, mas é fonte ética para as condutas políticas que a ela se destina. ${ }^{3}$

$\mathrm{Na}$ "sorte de inerência” a que Merleau-Ponty se refere acima, mora a inscrição ontológica da recíproca pertença entre o indivíduo e a comunidade, a vida singular e o mundo. No crivo desse entrecruzamento, poderíamos dizer, em última escala todo gesto nos situa no solo do "acontecimento global" e é, pois, este o movimento no qual "cada ato político [envolver] a totalidade da história” (Cf. Merleau-Ponty, 2000).

A filosofia merleau-pontiana se volta, pois, para o problema da diferença e da igualdade, por assim dizer, não como dois termos absolutos, mas como verso e reverso um do outro. O faz, doravante, mais do que se voltando para a circunscrição do outro como absolutamente outro, perguntando-se pelos existenciais comuns, os traços que colocam no horizonte da comunhão toda e quaisquer experiências e as torna co-possíveis de compreensão: "a comunicação entre os sujeitos sucessivos, como entre os sujeitos contemporâneos, não é o reencontro de pensamentos desencarnados em um céu de ideias invariáveis, é, ao contrário, a profunda afinidade de situações que se compreendem uma a outra em suas diferenças" (Merleau-Ponty, 2000, p. 34). Perguntando- se, pois, pelos elos que radicam "os momentos raros e preciosos em que acontece aos homens se reconhecerem e se encontrarem", como o dirá em Conversas de 1948 (Merleau-Ponty, 2002, p. 52). Neste sentido, escreverá em nota de trabalho no Visible et l'Invisible:

[f]ala-se sempre do problema de "outrem", da "intersubjetividade' etc. [...] Na realidade, o que é posto a compreender é, para além das "pessoas", os existenciais segundo os quais as compreendemos, e que são o sentido sedimentado de todas as nossas experiências voluntárias e involuntárias. Esse inconsciente a procurar não no fundo de nós, atrás das costas de nossa "consciência", mas diante de nós, como articulação de nosso campo. Ele é "inconsciente" pelo fato de que não é objeto, mas é isso pelo que os objetos são possíveis, é a constelação onde se lê nosso futuro - ele está entre eles como o intervalo das árvores entre as árvores, ou como seu nível comum. Ele é a Urgemeinschaftung de nossa vida intencional, o Ineinander dos outros em nós e de nós neles. [...] São esses existenciais que produzem o sentido [...] do que dizemos e do que entendemos. Eles são a armadura desse "mundo invisível" que, com a palavra, começa a impregnar todas as coisas que vemos (Merleau-Ponty, 2009, p. 231).

3 É no contexto dessas questões que vemos Lefort elaborar a sua pergunta pelo que ancora a igualdade de direitos tanto quanto sua noção de corpo social como dimensão simbólica da universalidade, como resposta à dificuldade de dizer/definir o nome-princípio em que se funda a defesa dos direitos humanos em sua consistência universal; bem como tematizar as relações reciprocas entre diretos humanos, política e democracia. 
Essas compreensões (e mudanças de acento) no que toca a núcleos conceituais caros à filosofia moderna terão implicações na tematização da ética em direção à qual nos debruçamos. Pensamos, por exemplo, que o sentido de uma ontologia indireta nos termos da irredutibilidade do Ser (do fluxo da vida) ao dito, em suma - guarda relações com a ética originária de que falamos alhures e terá consequências caras na perscrutação do não apriorismo normativo que a caracteriza. Aqui poderíamos mesmo falar de uma ética indireta, no sentido em que não pode ser expressa diretamente, no sentido em que está aquém da norma expressa. Uma ética implícita na criação e na abertura temporal ou, doutro modo, na indeterminação. Estas são a sua condição, posto ser a criação e a abertura temporal as ondulações da existência pelas quais a diferença vige, vive - donde falarmos em coexistência. Deste modo, haverá sempre um jogo entre os padrões racionais de uma moralidade social e a ação ética ela mesma, entre a sociedade e o indivíduo. Em tal jogo há, por vezes, "ruptura", transformação: é que o indivíduo pode encontrar outra verdade acerca de si mesmo e, como tal, criar outros modos de vida, outros modos morais de viver.

Tratar-se-ia, tal ética indireta, do apelo mudo, do apelo do mundo tal qual compreendido em Merleau-Ponty: "apelo renovado e insistente de um mistério familiar [isto é, comum a todos] e inexplicável de uma luz que aclarando o resto, conserva sua origem na obscuridade” (Merleau-Ponty, 2009, p. 71) solo comum onde radica toda linguagem, todo pensamento e toda ação.

Compreende-se que nossa espécie, engajada assim numa tarefa que jamais é terminada nem poderia o ser, e que não é chamada necessariamente a conseguir terminá-la, mesmo que relativamente, encontra nessa situação ao mesmo tempo um motivo de inquietude e um motivo de coragem. Os dois, a bem dizer, não são senão um. Porque a inquietude é vigilância, é a vontade de julgar, de saber o que se faz e o que se propõe. Se não há fatalidade boa, tampouco há fatalidade má e a coragem consiste em reportar-se a si e aos outros de modo que, através de todas as diferenças das situações físicas e sociais, todos deixem aparecer em sua própria conduta e em suas próprias relações a mesma chama, que faz com que os reconheçamos, que tenhamos necessidade de seu assentimento ou de sua crítica, que tenhamos um destino comum (Merleau-Ponty, 2002, p. 50-51).

É precisamente a coexistência - cuja experiência é sensível - a circunscrição ontológica da dimensão ética. Neste sentido, a experiência do ser é ética sem ser normativa. Toda normatividade, porém, está enraizada e deriva do mundo da vida, sendo a coexistência o princípio-reciprocidade dos agentes morais sem a polarização ou dualidades habituais. Nesta perspectiva, se há uma universalidade esta não é normativa - não é aquela da lei -, mas existencial: "é da 'presença originária' do sensível que vêm a evi- dência e a universalidade" (Merleau-Ponty, 2008, p. 279). Ela, a universaliade, enraiza-se, pois, na reversibilidade sensível que somos, carne em que vigora a afinidade/reciprocidade fundamental e nos aparece como horizonte de compromisso. Trata-se de sermos igualmente dispostos à existência, do igual pertencimento ao mundo - mundo comum. Tal igualdade cria e ancora normas historicamente - para resguardar-se - e perdoa - para não morrer, matar-se, posto ser ela instituída pela diferença/contingência, seu termo correlato. Por fim, parafraseando Merleau-Ponty, na perspectiva de uma ética existencial, já não nos tornaríamos bons, pela coerência com a normatividade moral apriorística, para superficialmente nos perdoar; mas sem medo de ter que perdoar (ou não perdoar), teríamos que ser compreensão (Cf. Merleau-Ponty, 1980). Tal perspectiva nos é cara para pensar questões prementes, tal como a pena de morte, por exemplo. Caberia nos perguntarmos: a solidariedade só caberia nas relações inseridas em um campo de reciprocidade/afinidade de comportamentos morais? Dos aliados?

Aqui, aparece uma diferença entre normatividade racional a priori, cujo caráter é prescritivo, e normatividade como horizonte de compromisso assentado numa ética profunda, por assim dizer, aquela do pertencimento sensível que nos apela, chama-nos de modo indireto, lembra-nos e desperta em nós tanto a disposição para a ação que quer "fazer tudo [a vida] andar em conjunto" (Merleau-Ponty, 2000, p. 149), como a vergonha de certos atos - em muitos casos. A primeira disposição, por certo, é um fenômeno derivado da segunda que, por sua vez, como apelo silencioso infinito, dá-nos aos estranhamentos de certas situações em que nos vemos (seja na ondulação da vida pessoal, seja naquela da vida social) e, como tal, à abertura e criação de modos de vida movimento em que se situam as transformações das normas oficiais, positivas (lembremos, por exemplo, no caso do Brasil, da lei Maria da Penha, do Estatuto da Criança e do Adolescente, Lei dos Crimes Ambientais etc., como dos tantos acordos internacionais), tanto quanto das normas costumeiras.

A perspectiva de uma ética enraizada na coexistência e no comum pertencimento ao mundo da vida, tal como abordada, contrapõe-se à pretensão de justificação racional unilateral e a priori de inspiração kantiana. A afirmação de que se há uma universalidade esta não é normativa mas existencial, remete-nos ao deslocamento da justificativa da conduta ética do apriorismo unilateral para o mundo da vida em movimento, para a existência sempre em situação, portando coexistência. Neste crivo, "a moralidade não é dada, mas a ser feita” (Merleau-Ponty, 1996a, p. 79).

Por fim, trata-se a inscrição ontológica, originária, da conduta ética de uma intuição, o que dela decorre implica ação - melhor: ela inspira ação. E sendo tal disposição ética não posta de início, mas uma tarefa, ela é radicada na história, portanto no inacabamento. Tais traços não lhe são impedimentos, mas, ao contrário, vias por onde vive - vige. E é isto (o apelo calado de tal intuição) que nos remete continuamente ao julgamento das normas no 
que toca ao caráter ético (ou não) delas, por vezes transformando-as. Com isto, entretanto, não estamos a dizer "que o homem possa, subitamente, dispensar a normatividade, mas ela deve submeter-se ao crivo de uma crítica acirrada" (Bornheim, 2015, p. 65). Nesta direção, ao tomarmos "a articulação em profundidade entre a experiência sensível e a ação" (Barbaras, 2018, s.n.) em seu parecer sobre relatório de pesquisa, 2018) como o lugar de concernência da ética indireta de que falamos e não mais o apriorismo da prescrição, não buscamos com isto resolver a questão da normatividade, mas explorá-la, indo em via diversa às fontes da normatividade moral tais quais as encontramos na tradição filosófica. E é no movimento de exploração destas questões e não na resolução delas que vemos a dimensão ética da filosofia de Merleau-Ponty aparecer: encarnada e, como tal, pré-reflexível, aquém da lei, indireta.

$$
* * *
$$

Do ponto de vista da disposição ética, da ação ética propriamente, temos no Cuidado o seu assento, posto compreendermo-nos, a nós todos, sempre como relação originária e contingência - e como tal, fragilidade. Isto solicita, simultaneamente, diligência e alento na ação, em um fluxo de atenção que, digamos, não cessa. Disposição esta compreendida no que Merleau-Ponty designará - só muito depois dei-me conta "virtude sem nenhuma resignação" no final do prefácio de Signes: [...] "A conclusão não é a revolta, é a virtude sem nenhuma resignação. Decepção para quem acreditou na salvação e em um só meio de salvação em todas as ordens" (Merleau-Ponty, 2008, p. 61 - itálicos do autor). O que "reside na coragem de enfrentar, cada vez que se coloca, o problema da relação do homem com o homem, qualquer que seja a contingência dos valores" (Carron, 2012, p. 198). A título de melhor explicitar isso que ensaiamos, penso que aqui é bem-vinda a afirmação de Derrida em entrevista publicada no suplemento Mais! da Folha de S. Paulo, em maio de 2001:

Um dos paradoxos do que tento propor é que só há ética, só há responsabilidade moral, como se diz, ou decisão ética ali onde não há mais regras ou normas éticas. Se há regras ou se há uma ética disponível, ou um conjunto de regras, nesse caso basta saber quais são as normas e proceder a sua aplicação, e assim, não há mais decisão ética. $\mathrm{O}$ paradoxo é que, para haver decisão ética, é preciso que não haja ética, que não haja regras nem normas prévias.

Claro está que quando Derrida (2001) afirma “para haver decisão ética, é preciso que não haja ética”, com esta última o autor se refere à ética compreendida nos termos da prescrição, ao códigos positivos. Mas, um tal pensamento nada tem de adesão às perspectivas ético-políticas do liberalismo e ao elogio do individualismo por ele sustentada - como algumas leituras apressadas poderiam depreender. Ao contrário, a disposição ética implicada nas compreensões acima, assunção radical que é do comum pertencimento (ao mundo, à região, ao país, à cidade, aos lugares por onde se vive, enfim), correlato à coexistência e a uma certa "solidariedade na origem” (Merleau-Ponty, 1996c, p. 217), para parafrasear Merleau-Ponty, toma-o (o comum pertencimento) como um bem (bem comum), o que sugere contínuo e simultaneamente, no que toca ao pensamento e à ação, engajamento e autenticidade.

Nesse movimento, o julgamento implica uma disposição compreensiva alargada: o sujeito, comprometido com a compreensão de si mesmo, compreende os entrecruzamentos do mundo em que vive (já que o "si" é sempre já relação), compreende, pois, o fenômeno da coexistência. Com efeito, dirá Merleau-Ponty sobre a sua filosofia, "tudo se resume a isto: fazer uma teoria da percepção e da compreensão que mostre que compreender não é constituir na imanência intelectual, que compreender é apreender pela coexistência” (Merleau-Ponty, 2009, p. 239). Ora, numa tal perspectiva, do julgamento - era sobre isto que falávamos - não poderia emergir qualquer perspectiva de anulação do outro - do outro argumento, do outro lado, como se diz; do outro que vive -, mas apenas escolhas situadas. Afinal, "não se pode ser justo sozinho [...] ao sê- lo sozinho se cessa de o ser" (Merleau-Ponty, 1989, p. 44). Para a vida inteira viver é preciso ser menos - menos forte, por assim dizer. "Enquanto vivemos com os outros, nenhum julgamento de nós sobre eles torna possível excetuar-nos e os botar à distância” (Merleau-Ponty, 1989, p. 44). Há, pois, "sempre laços, mesmo e sobretudo quando recusamos aceitá-lo” (Merleau-Ponty, 1996b, p. 28).

A coexistência, radicalmente assumida, implica o conflito - só existimos, e mesmo a contragosto!, com ou outros -, fenômeno que se contrapõe à ideia de síntese, resolução final, poder de encerramento voluntário. Nesta perspectiva, o conflito é constitutivo da ética que perscrutamos - questão que apenas enunciamos mas não adentraremos. Há aí, no horizonte ético de que falamos, consequências e desafios pungentes. Nele " $\mathrm{O}$ mal não é criado por nós ou por outros, ele nasce no tecido que fiamos entre nós e que nos sufoca. Que novos homens assaz duros serão assaz pacientes para o refazer verdadeiramente?" (Merleau-Ponty, 2008, p. 61).

Por fim, embora Merleau-Ponty tematize a questão do Outro, circunscrevendo-a, sobretudo, na relação dos homens com os homens, pensamos que a sua filosofia - a reversibilidade inerente ao Ser bruto, o Ser de indivisão que ela sustenta -, dá-nos a pensar a ética numa teia de relações que ultrapassa tal limite - aquele das relações do homem com o homem - e que se dilata para o vasto mundo das relações em que se vive - vive-se, inevitavelmente, sempre em relação com tudo que há, com todos os vivants. Donde a compreensão de que a filosofia de Merleau-Ponty fornece indicações para uma disposição ética que se alarga para além do plano antropológico, estendendo os sentidos contíguos de fragilidade, cuidado e responsabilidade para além da atenção restrita aos seres humanos - embora deles advenham a ação. Tratar-se-ia, como reportamos alhures, de uma ética profunda, que compreende o sentido de autonomia sempre no crivo de um co-pertencimento inultrapassável e recolhe as consequências que daí decorrem: toma as coisas e outras espécies no crivo do seu cuidado. 


\section{Conclusão}

Mas não desejamos, doravante, porque não é caso, aprofundar essas questões até aqui traçadas na direção de uma ética em Merleau-Ponty - elas mesmas partilhadas com Renaud Barbaras no curso de um estágio de pesquisa em Paris. Se cá apareceram, foi no fito de explicitação dos ecos do diálogo que fiam esse texto, este sim - o diálogo - seu elemento central. Um diálogo fecundo em pensamento, como em geral o foram aqueles que tive com a obra de Barbaras ou, por assim dizer, com o autor ele mesmo. Sua fecundidade, por certo, mora no recolhimento da "separação fundamental a partir da qual o que separa, torna-se relação”, como nos faz ver Blanchot na epígrafe com que iniciamos este artigo (Blanchot, 1971, p. 201).

Relação, pois, que ao recolher nossas diferenças - e com elas nossos conflitos -, opõe-se "à impostura de uma razão que se satisfaz de ter razão por si” (Merleau-Ponty, 1980, p. 308) e cuja vida nos ensina que "procurar o acordo conosco e com outrem, numa palavra a verdade, não somente na reflexão $a$ priori e no pensamento solitário, mas ainda na experiência das situações concretas e no diálogo com os outros vivos" (Merleau-Ponty, 1980, p. 308), faz-nos vivants e, como tal, movimento, criação. E é este o campo de sentido no qual falamos em amizade logo no início deste artigo. Afinal, em contraposição à misantropia - que diz daquele que "não encontra ninguém com quem deseje partilhar o mundo, que não considera ninguém digno de gozar com ele o mundo, a natureza e o cosmos" (Arendt, 1991, p. 36) -, diz Hannah Arendt que já "os gregos davam ao que se alcança no diálogo da amizade o nome de philanthopia, 'amor do homem', uma vez que se manifesta numa vontade de partilhar o mundo" (Arendt, 1991, p. 36). Um mundo comum, em cuja partilha - participação e diálogo, por assim dizer - mora o pensamento ético.

\section{Referências}

Arendt, H. (1991). Homens em tempos sombrios. Lisboa: Relógio D’Água.

Barbaras, R. (2018). Parecer de relatório científico, Projeto Para pensar uma ética: filosofia e mundo comum em Merleau-Ponty / Fapesp. Paris [s.n.].

Barbaras, R. (2009). La perception: essai sur le sensible. Paris: Vrin.

Blanchot, M. (1971). L'amitié. Paris: Gallimard.

Bornheim, G. (2015). Temas de filosofia. São Paulo: Edusp.

Carron, G. (2012). A ética política de Merleau-Ponty: o problema do humanismo. Doispontos, 9 (1), 181-200.

Chauí, M. (2002). Experiência do pensamento: ensaios sobre a obra de Merleau-Ponty. São Paulo: Martins Fontes.

Derrida, J. (2001). "Entrevista”, in Mais! / Folha de S. Paulo, maio.

Leopoldo e Silva, F. (2018). Prefácio, In Vânia Vicente, Arte e Verdade em Merleau-Ponty: ecos de uma imbricação.
São Paulo: Humanitas, Fapesp.

Lispector, C. (1998). Perto do coração selvagem. Rio de Janeiro: Rocco.

Loparic, Z. (2004). Ética e finitude. São Paulo: Escuta.

Matos Dias, I. (2006). Para uma fenomenologia da subjectividade: a experiência da vídeo-arte de Bill Viola, In Maria José Cantista (Org.), Subjetividade e racionalidade, uma abordagem fenomenológico-hermenêutica. Porto: Campo das Letras.

Merleau-Ponty, M. (1945). Phénoménologie de la perception. Paris: Gallimard

Merleau-Ponty, M. (1980). Humanisme et terreur. Paris: Gallimard.

Merleau-Ponty, M. (1989). Éloge de la philosophie. Paris: Gallimard.

Merleau-Ponty, M. (1995). La nature - notes de cours du Collège de France. Paris: Seuil.

Merleau-Ponty, M. (1996a). Le primat de la perception et ses conséquences philosophiques. Paris: Verdier.

Merleau-Ponty, M. (1996b). Sens et non-sens. Paris: Gallimard.

Merleau-Ponty, M. (1996c). Notes de cours: 1959-1961. Paris: Gallimard.

Merleau-Ponty, M. (2000). Parcours deux: 1951-1961. Paris: Verdier, 2000.Parcours deux: 1951-1961. Paris: Verdier.

Merleau-Ponty, M. (2002). Causeries. Paris, Seuil.

Merleau-Ponty, M. (2008). Signes. Paris: Gallimard.

Merleau-Ponty, M. (2009). Le visible et l'invisible. Paris: Gallimard.

Merleau-Ponty, M. (2016). Entretiens avec Georges Charbonnier e autres dialogues, 1946-1959. Paris: Verdier.

Vânia Vicente possui Doutorado em Filosofia pela Universidade de São Paulo (2014), instituição na qual também realizou pesquisa de Pós-Doutorado na mesma área, no período de 2014 a 2018. Cursou Mestrado em Filosofia pela Universidade Federal de Pernambuco (2006) e Graduação em História pela Universidade Federal de Alagoas (2000). É colaboradora do Grupo de Estudos Espinosanos (USP). Além de assinar diversos textos, é autora de Arte e verdade em Merleau-Ponty: ecos de uma imbricação (São Paulo: Humanitas, 2018). E-mail: vsantos1985@gmail.com

Recebido em 14.10.2018

Aceito em 23.01.2019 